\title{
Genetic parameters for milk yield, lactation length and calving intervals of Murrah buffaloes from Brazil
}

\author{
Carlos Henrique Mendes Malhado ${ }^{1}$, Ana Claudia Mendes Malhado², Alcides de Amorim \\ Ramos $^{3}$, Paulo Luiz Souza Carneiro ${ }^{1}$, Julio César de Souza ${ }^{4}$, Akin Pala ${ }^{5}$
}

\author{
1 Universidade Estadual do Sudoeste da Bahia. \\ 2 Universidade Federal do Alagoas. \\ ${ }^{3}$ Universidade Estadual Paulista. \\ ${ }^{4}$ Universidade Federal do Mato Grosso do Sul. \\ ${ }^{5}$ Canakkale Onsekiz Mart University, Ziraat Fak.
}

\begin{abstract}
The major objective of this study was to estimate heritability and genetic correlations between milk yield (MY) and calving interval (CI) and lactation length (LL) in Murrah buffaloes using Bayesian inference. The database used belongs to the genetic improvement program of four buffalo herds from Brazil. To obtain the estimates of variance and covariance, bivariate analyses were performed with the Gibbs sampler, using the program MTGSAM. The heritability coefficient estimates were $0.28,0.03$ and 0.15 for MY, CI and LL, respectively. The genetic correlations between MY and LL was moderate (0.48). However, the genetic correlation between MY and CI showed large HPD regions (highest posterior density interval). Milk yield was the only trait with clear potential for genetic improvement by direct mass selection. The genetic correlation between MY and LL indicates that indirect selection using milk yield is a potentially beneficial strategy. The interpretation of the estimated genetic correlation between MY and CI is difficult and could be spurious.
\end{abstract}

Key Words: genetic correlation, Gibbs sampler, heritability

\section{Introduction}

The water buffalo (Bubalus bubalis) was originally bred in Asia and is now a dairy animal widespread throughout the world (Jain et al., 2007; Borghese 2010). Recent estimates suggest that there are about 2.8 million buffalos distributed across all Brazilian states (Ramos et al., 2006) out of a global population of more than 174 million individuals (FAO, 2006). This species has undergone a major expansion in Brazil and, perhaps surprisingly, has had an even higher population growth than cattle in recent years (Malhado et al., 2007). In contrast, the world buffalo population has increased by approximately 18 million in the last 10 years, showing an annual increase of only about $1.13 \%$ (Kumar \& Singh, 2010).

The lifetime production of a dairy cow is an indication of its utility and is influenced by key fertility parameters such as calving intervals, length of each lactation and probability of surviving from one lactation period to the next (HosseinZadeh, 2011). Likewise, the economic return of buffalo milk depends on the milk production and reproductive efficiency of animals - the latter being particularly affected by calving interval (Ramos et al., 2006).

Breeding buffaloes for increased milk production and reproductive efficiency may not be straightforward.
Genetic antagonism has been reported between traits associated with reproductive efficiency andmilkproduction in cattle (Marti \& Funk, 1994). However, these findings are by no means universal and some researchers have reported favorable associations between reproductive traits and milk yield in both dairy cattle (Hossein-Zadeh, 2011) and buffaloes (Ramos et al., 2006; Malhado et al., 2009).

Abdallah \& McDaniel (2000) concluded that improvement in yield traits is penalized by a decrease in the fertility of cows because of an increase in the average time from calving to conception. Thus, the economic gain due to the increased milk yield may be counteracted by economic loss due to delay in conception, losing the gain from selection for yield traits.

The prediction of breeding values and estimation of variance components are essential components of breeding programs aimed at enhancing economically important phenotypic traits through selective breeding. The typical procedure of estimation/prediction is normally based on restricted maximum likelihood/best linear unbiased prediction (REML/BLUP). However, because REML/ BLUP uses approximation and assumptions of asymptotic normality, it provides only approximate confidence intervals for genetic parameters and the distribution and variance of the estimators are unknown (Resende, 2002). A potential 
solution is the adoption of a Bayesian approach that allows the construction of exact probability intervals for estimates of genetic parameters.

The major objective of the present study was to estimate heritabilities and genetic correlations of milk yield (MY) with calving intervals (CI) and lactation length (LL) in water buffaloes using Bayesian inference (BI).

\section{Material and Methods}

Data on milk yield (2910), lactation length (2910) and calving interval (1721) were collected from 702 Murrah buffaloes born between 1982 and 2003 of four herds from Brazil. The average traits were $1631.5 \pm 642.1 \mathrm{~kg}$, $269.4 \pm 43.1$ days and $411.0 \pm 80.1$ days for MY, LL and CI, respectively.

Variance components, heritability coefficients and repeatabilities were calculated for milk yield, lactation length and calving interval. We also estimated the genetic, environmental and phenotypic correlations between MY and LL and MY and CI.

Bivariate analyses were performed with the Gibbs sampler to obtain the estimates of variance and covariance, using the program MTGSAM (Multiple Trait Gibbs Sampling for Animal Models) as described by Van Tassell \& Van Vleck (1995).

The model adopted, represented in matrix notation, was

$$
y=X \beta+Z a+W p+e
$$

Where $y$ is a vector of observed traits (MY, LL and CI); $X$ is the incidence matrix of fixed effects; $\beta$ is a vector of fixed effects (CG, calving orders and milking frequency); $Z$ is the incidence matrix of additive genetic random effects, $a$ is a vector of additive genetic random effects; $W$ is the incidence matrix of permanent environmental random effect; $p$ is a vector of permanent environmental random effects; and $e$ is a vector of random-error effects.

Four birth seasons (January to March, April to June, July to September and October to December) were used for the formation of the contemporary groups (CG). The CG contained animals of the same herd, season and year of parturition.

The prior distribution for co(variance) components of the genetic effects was an inverted Wishart. The MTGSAM uses the Gauss-Seidel iterative method in the mixed model equation to obtain an initial value for the fixed and random effects to be used in the Gibbs sampler. The initial numbers were arbitrarily obtained using a single chain with 150,000 iterations and a burn-in period of 25,000 samples was used with samples taken at each 25 cycles. The convergence diagnosis was analyzed through the Geweke method (1992) using the algorithm implemented on software $\mathrm{R}$ through the package BOA (Bayesian Output Analysis; Smith, 2005).

The descriptive statistics (mean, median, mode and standard deviation) of the a posteriori distribution for each parameter were obtained from effective samples using the software SAS (Statistical Analysis System, version 9.1). The highest posterior density (HPD) region or confidence interval provides the interval that includes $95 \%$ of samples and is a measure of reliability. The HPD can also be applied to non-symmetric distributions (Hyndman, 1996).

\section{Results and Discussion}

The means, medians and modes of estimates of variance components and genetic parameters for milk yield and lactation length were similar (Table 1). This is in accordance with Carlin \& Louis (2000), who observed that similar values are expected for an a posteriori marginal density that follows a normal distribution. According to Wright et al. (2000), the mode is the most appropriate position measure for a posteriori distributions, and best reflects the highest frequency values (maximum distribution). It is important to emphasize that other measures of central tendency such as the mean and median can also summarize a posteriori distributions, especially if the densities are approximately symmetrical - circumstances under which such measures are similar. On the other hand, the calving intervals showed different results to position measures and nonsymmetric distribution.

The heritability estimate for milk yield was moderate (mode $=0.28)$, suggesting that this trait has enough additive genetic variation to respond well to direct mass selection. Studies on buffaloes using Bayesian inference (BI) reported heritabilities of 0.22 (Aspilcueta-Borquis et al., 2010) and 0.16 (Malhado et al., 2012) for the Murrah and Jaffarabadi breeds, respectively. Ramos et al. (2006), Tonhati et al. (2008) and Rodrigues et al. (2010) reported heritabilities of $0.21,0.19$ and 0.25 using REML on the Murrah breed. However, much higher results $(0.39)$ were reported by Araújo et al. (2008) using BI on the same breed.

The heritability for lactation length was 0.15 (Table 1), which indicates small possibility of direct selection for the trait. Several studies have reported lower values than this: 0.08 (REML) for crossbred buffaloes (Malhado et al., 2009), 0.10 (REML) for Murrah buffaloes (Rodrigues et al., 2010) and 0.10 (BI) for the Jaffarabadi breed (Malhado et al., 2012).

Heritability for CI was zero (mode $=0.00$ ). This is in agreement with values reported in the literature for dairy cattle (Abdallah \& McDaniel 2000; Silva et al., 2001) 
Table 1 - Means, standard deviation (SD), median, mode and highest a posteriori density interval (HPD) of the genetic parameters for milk yield (MY), lactation length (LL) and calving interval (CI)

\begin{tabular}{|c|c|c|c|c|c|c|c|}
\hline \multirow{2}{*}{ Traits } & \multirow{2}{*}{ Parameters } & \multirow{2}{*}{ Mean } & \multirow{2}{*}{$\mathrm{SD}$} & \multirow{2}{*}{ Median } & \multirow{2}{*}{ Mode } & \multicolumn{2}{|c|}{ HPD } \\
\hline & & & & & & Low limit & High limit \\
\hline \multirow[t]{6}{*}{ MY } & $\sigma^{2} \mathrm{a}$ & 84221.70 & 15144.22 & 83824.00 & 83151.80 & 56941.68 & 115458.60 \\
\hline & $\sigma^{2}$ pe & 31746.39 & 10969.00 & 31443.19 & 32461.23 & 11231.70 & 51908.61 \\
\hline & $\sigma^{2} \mathrm{e}$ & 184770.38 & 6522.83 & 184827.90 & 18529.54 & 171751.15 & 197921.10 \\
\hline & $\sigma^{2} p$ & 300738.48 & 11257.90 & 300738.48 & 299834.49 & 280006.93 & 323010.60 \\
\hline & $\mathrm{h}^{2}$ & 0.28 & 0.04 & 0.28 & 0.28 & 0.19 & 0.36 \\
\hline & $\mathrm{R}$ & 0.38 & 0.02 & 0.38 & 0.38 & 0.34 & 0.42 \\
\hline \multirow[t]{6}{*}{ LL } & $\sigma^{2} \mathrm{a}$ & 265.64 & 59.23 & 263.75 & 259.85 & 151.78 & 383.11 \\
\hline & $\sigma^{2}$ pe & 33.25 & 33.91 & 21.89 & 7.54 & 2.80 & 105.20 \\
\hline & $\sigma^{2} \mathrm{e}$ & 1508.02 & 52.09 & 1507.03 & 1497.00 & 1404.36 & 1603.52 \\
\hline & $\sigma^{2} \mathrm{p}$ & 1806.90 & 58.05 & 1804.81 & 1791.43 & 1697.77 & 1923.4 \\
\hline & $h^{2}$ & 0.15 & 0.03 & 0.15 & 0.15 & 0.09 & 0.21 \\
\hline & $\mathrm{R}$ & 0.17 & 0.02 & 0.16 & 0.16 & 0.13 & 0.21 \\
\hline \multirow[t]{6}{*}{ CI } & $\sigma^{2} \mathrm{a}$ & 485.15 & 397.79 & 400.87 & 109.75 & 7.97 & 1252.72 \\
\hline & $\sigma^{2}$ pe & 426.88 & 373.01 & 332.00 & 91.02 & 0.60 & 11150.84 \\
\hline & $\sigma^{2} \mathrm{e}$ & 14314.30 & 611.60 & 14295.27 & 14253.88 & 13144.33 & 15520.15 \\
\hline & $\sigma^{2} p$ & 15226.63 & 574.86 & 15217.21 & 15309.88 & 14127.33 & 163631.68 \\
\hline & $\mathrm{h}^{2}$ & 0.03 & 0.021 & 0.03 & 0.00 & 0.00 & 0.08 \\
\hline & $\mathrm{R}$ & 0.06 & 0.026 & 0.06 & 0.06 & 0.01 & 0.11 \\
\hline
\end{tabular}

$\sigma^{2} \mathrm{a}$ - additive genetic variance; $\sigma^{2}$ pe - permanent environment variance; $\sigma^{2} \mathrm{e}$ - residual variance; $\sigma^{2} \mathrm{p}$ - phenotypic variance; $\mathrm{h}^{2}$ - heritability; R - repeatability.

and buffaloes (Ramos et al., 2006). However, studies on buffaloes by Penchev (1998), Mahdy et al. (1999), Aziz et al. (2001) and Cassiano et al. (2004) reported values equal to $0.16,0.17,0.07$ and 0.26 , respectively.

Heritability estimates of calving interval are obtained using field data, which are subject to interference from the breeder. For example, measures of calving interval frequently omit dams culled for low production or reproductive problems, a strategy that can result in reduction of additive genetic variance. Additionally, this low heritability implies that variations in these traits are, to a large extent, influenced by environmental factors such as herd management policies. New studies with censored data can overcome this problem.

The a posteriori distributions of MY and LL traits were symmetric and close to those expected in a normal distribution (Figures 1 and 2). However, the CI traits were positively asymmetric, showing significant differences between the mode, mean and median (Figure 3).

The repeatability of the traits were $0.38,0.16$ and 0.06 (modes) for MY, LL and CI, respectively (Table 1), indicating that the selection of animals based on limited information about the first lactation can only be used to improve milk yield. Ramos et al. (2006), Rodrigues et al. (2010) and Malhado et al. (2012) reported repeatability coefficients of $0.32,0.33$ and 0.58 for MY, respectively.

The estimated correlations between milk yield and the other two traits were positive (Table 2; Figures 4 and 5). However, the genetic correlation between MY and CI showed a large HPD region. Similar results were reported by

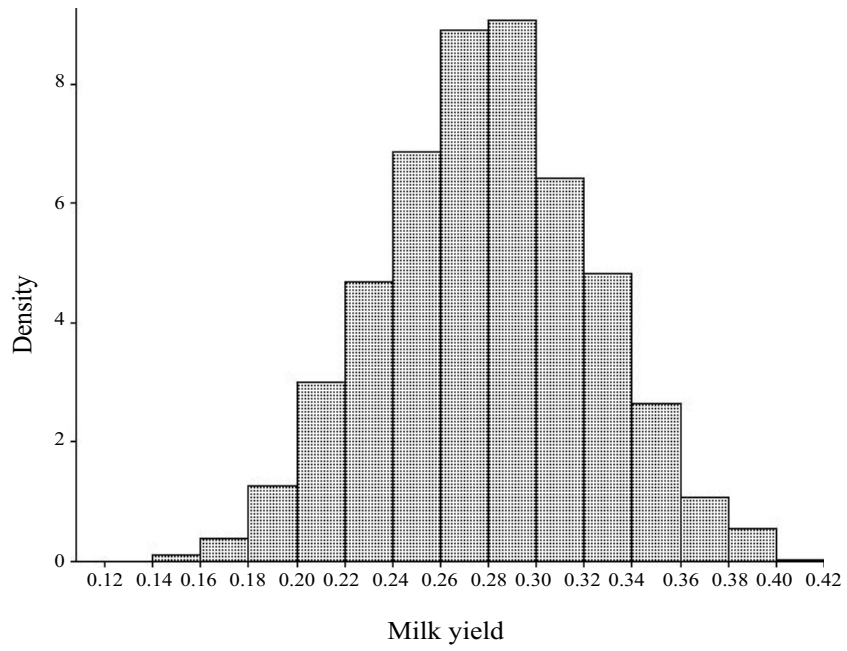

Figure 1 - A posteriori distribution for heritability for milk yield estimated by Bayesian inference.

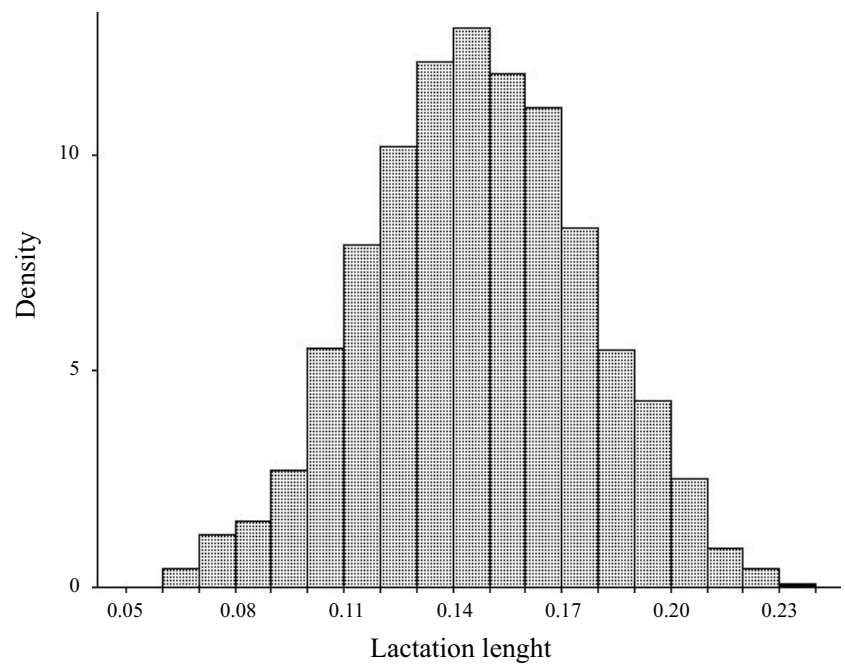

Figure 2 - A posteriori distribution for heritability for lactation length estimated by Bayesian inference. 
Table 2 - Environmental, phenotypic and genetic correlations between milk yield (MY) with lactation length (LL) and calving interval (CI)

\begin{tabular}{|c|c|c|c|c|c|c|c|}
\hline \multirow{2}{*}{ Correlation } & \multirow{2}{*}{ Traits } & \multirow{2}{*}{ Mean } & \multirow{2}{*}{$\begin{array}{c}\text { Highest standard } \\
\text { deviation }\end{array}$} & \multirow{2}{*}{ Median } & \multirow{2}{*}{ Mode } & \multicolumn{2}{|c|}{ A posteriori density interval } \\
\hline & & & & & & Low limit & High limit \\
\hline \multirow[t]{2}{*}{ Genetic } & LL & 0.47 & 0.11 & 0.47 & 0.48 & 0.23 & 0.69 \\
\hline & CI & 0.40 & 0.30 & 0.38 & 0.35 & -0.07 & 0.99 \\
\hline \multirow{2}{*}{ Phenotypic } & LL & 0.47 & 0.031 & 0.47 & 0.47 & 0.41 & 0.53 \\
\hline & CI & 0.08 & 0.030 & 0.08 & 0.08 & 0.03 & 0.14 \\
\hline \multirow[t]{2}{*}{ Environmental } & LL & 0.52 & 0.02 & 0.52 & 0.52 & 0.48 & 0.56 \\
\hline & CI & 0.07 & 0.032 & 0.07 & 0.07 & 0.01 & 0.13 \\
\hline
\end{tabular}

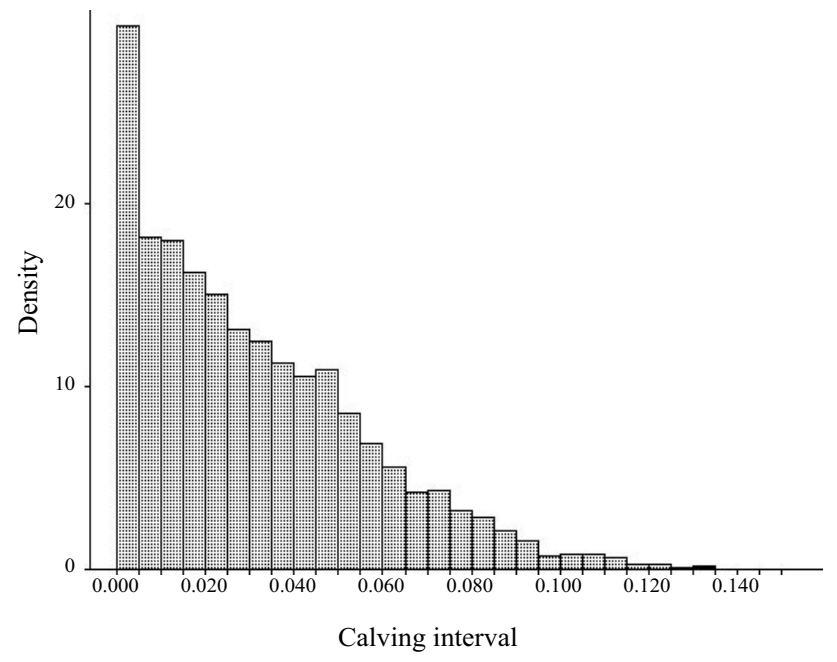

Figure 3 - A posteriori distribution for heritability for calving intervals estimated by Bayesian inference.

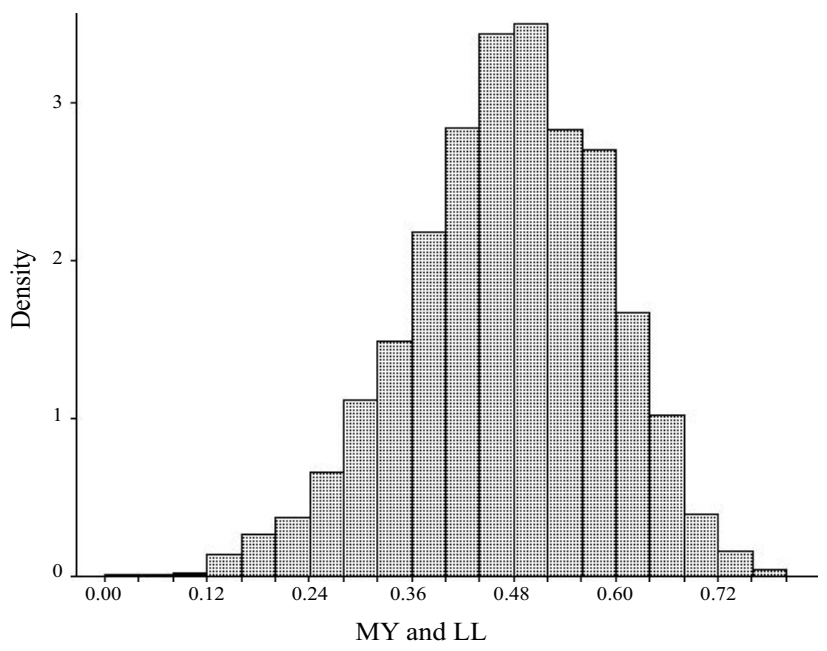

Figure 4 - A posteriori distribution for genetic correlation of milk yield (MY) and lactation length (LL) estimated by Bayesian inference.

Aspilcueta-Borquis et al. (2010), who estimated the genetic correlations of milk yield and different milk quality traits.

The correlations (genetic, phenotypic and environmental) between MY and LL were moderate (from 0.47 to 0.52 ). High genetic correlations between these two traits in

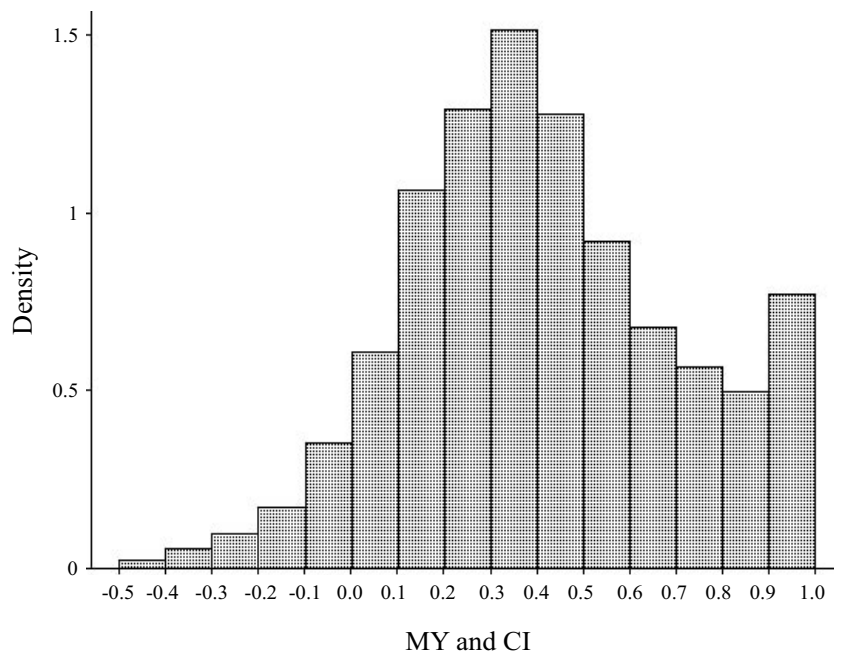

Figure 5 - A posteriori distribution for genetic correlation of milk yield (MY) and calving interval (CI) estimated by Bayesian inference.

buffaloes have been reported in other studies (0.89 Malhado et al., 2009; 0.72 - Rodrigues et al., 2010) using the REML method. These results indicate that selection for milk yield could promote moderate changes in the lactation length.

The three position measures for genetic correlation of MY and CI ranged from 0.35 to 0.40 . However, the high standard deviations and large HPD complicate the interpretation of the parameter. Ramos et al. (2006) used REML in the same set of data and estimated a negative correlation of -0.22 . Malhado et al. (2009) have also reported a negative value of -0.25 .

\section{Conclusions}

Among the studied traits, milk yield is the only one with clear potential for genetic improvement by direct selection. The genetic correlation between milk yield and lactation length indicated that indirect selection using milk yield is a potentially beneficial strategy. The interpretation of the estimated genetic correlation between milk yield and calving interval is difficult and could be spurious. 


\section{Acknowledgments}

Thanks to Dr Richard Ladle for insightful comments and for proof-reading the manuscript.

\section{References}

ABDALLAH, J.M.; McDANIEL, B.T. Genetic parameters and trends of milk, fat, days open and body weight after calving in North Carolina experimental herds. Journal of Dairy Science, v.83, p.1364-1370, 2000.

ARAÚJO, C.V.; CARDOSO, A.M.C.; RAMOS, A.A. et al. Genetic parameters and heterogeneity of variance to milk yield in Murrah breed using Bayesian inference. Asociación Latinoamericana de Producción Animal, v.16, p.234-240, 2008.

ASPILCUETA-BORQUIS, R.R.; ARAUJO NETO, F.R.; BALDI, F. et al. Genetic parameters for buffalo milk yield and milk quality traits using Bayesian inference. Journal Dairy Science, v.93, p.2195-2201, 2010.

AZIZ, M.A.; SCHOEMAN, S.J.; JORDAAN, G.F. et al. Genetic and phenotypic variation of some reproductive traits in Egyptian buffalo. South African Journal of Animal Science, v.31, p.195-199, 2001.

BORGHESE, A. Development and perspective of Buffalo and Buffalo market in Europe and near east. Revista Veterinaria, v.21, p.20-31, 2010 (sup.).

CARLIN, B.P.; LOUIS, T.A. Bayes and empirical bayes methods for data analysis. 2.ed. London: Chapman and Hall, 2000. 419p.

CASSIANO, L.A.P.; MARIANTE, A.S.; McMANUS, C. et al. Genetic parameters of production and reproduction traits of buffaloes in the Brazilian Amazon. Pesquisa Agropecuária Brasileira, v.39, p.451-457, 2004.

FOOD AND AGRICULTURE ORGANIZATION - FAO. Water buffalo: an asset undervalued. FAO Regional Office for Asia and the Pacific, Bankok, Thailand. 2006. p.1-6.

GEWEKE, J. Evaluating the accuracy of sampling-based approaches to the calculations of posterior moments. In: BERNADO, J.M.; BERGER, J.O.; DAWID, A.P. et al. (Eds). Bayesian statistics. New York: Oxford Universuty, 1992. p.169-193.

HYNDMAN, R.J. Computing and graphing highest density regions. American Statistician, v.50, p.120-126, 1996.

HOSSEIN-ZADEH, N.G. Estimation of genetic and phenotypic relationships between age at first calving and productive performance in Iranian Holsteins. Tropical Animal Health Production, v.43, p.967-973, 2011

JAIN, A.K.; KUMAR, R.; MEHRA, M.L. et al. Incidende of inbreeding and its effect on production traits in a graded Murrah herd. Indian Journal of Animal Sciences, v.77, p.1155-1157, 2007.

KUMAR, R.; SINGH, R. Buffalo production system in India. Revista Veterinaria, v.21, p.32-37, 2010 (sup.).
MALHADO, C.H.M.; RAMOS, A.A.; CARNEIRO, P.L.S. et al. Genetic and phenotypic parameters for milk production of Murrah buffaloes. Revista Brasileira de Zootecnia, v.36, p.376-379, 2007.

MALHADO, C.H.M.; RAMOS, A.A.: CARNEIRO, P.L.S. et al. Genetic parameters of reproductive and productive traits in crossbreed water buffaloes in Brazil. Revista Brasileira de Saúde e Produção Animal, v.10, p.830-839, 2009.

MALHADO, C.H.M.; MALHADO, A.C.M., RAMOS, A.A. et al. Genetic parameters by Bayesian inference for dual purpose Jaffarabadi buffaloes. Archiv Tierzucht, v.6, p.567-576, 2012.

MAHDY, A.E.; EL-SHAFIE, O.M.; AYYAT, M.S. Genetic study and sire values for some economic traits in Egyptian buffaloes. Alexandria Journal of Agricultural Research, v.44, p.15-35, 1999.

MARTI, C.F.; FUNK, D.A. Relationship between production and days open at different level of herd production. Journal Dairy Science, v.77, p.1682-1690, 1994.

PENCHEV, P. Phenotypic and genotypic evaluation of the buffalo population bred in Bulgaria. Bulgarian Journal of Agricultural Science, v.4, p.463-469, 1998.

RAMOS, A.A.; MALHADO, C.H.M.; CARNEIRO, P.L.S. et al. Phenotypic and genetic characterization of the milk yield and calving interval in buffalo of the Murrah breed. Pesquisa Agropecuária Brasileira, v.41, p.1261-1267, 2006.

RESENDE, M.D.V. Biometric genetic and statitical in improvement of perennial. Brasília: Embrapa Informação Tecnológica, 2002. 975p.

RODRIGUES, A.R.; MARQUES, J.R.F.; ARAÚJO, C.V. et al. Estimation of genetic parameters of dairy buffaloes productive characteristics Eastern Amazon. Arquivo Brasileiro de Medicina Veterinária e Zootecnia, v.62, p.712-717, 2010

SILVA, M.V.G.B.; COBUCI, J.A.; FERREIRA, W.J. et al. Correlated responses in the reproductive traits in the breeding program of Mantiqueira cattle for milk production. Revista Brasileira de Zootecnia, v.30, p.1228-1235, 2001.

SMITH, B.J. [2005]. Bayesian output analysis program (BOA) for MCMC. Available at: $<$ http://www.public-health.uiowa.edu/boa/boa $>$. Accessed on: Mar. 15, 2011.

TONHATI, H.; CERÓN-MUÑOZ, M.F.; OLIVEIRA, J.A. et al. Testday milk yield as a selection criterion for dairy buffaloes (Bubalus bubalis Artiodactyla, Bovidae). Genetic Molecular Biology, v.31, p.674-679, 2008.

TOZER, P.R.; HEINRICHS, A.J. What affects the costs of raising replacement dairy heifers: a multiple-component analysis. Journal of Dairy Science, v.84, p.1836-1844, 2001.

VAN TASSELL, C.P.; VAN VLECK, L.D. A manual for use of MTGSAM. A set of FORTRAN programs to apply Gibbs sampling to animal models for variance components estimation (DRAFT). Lincoln: Department of Agriculture, Agricultural Research Service, 1995. 86p.

WRIGHT, D.R.; STERN,H.S.; BERGER, J. Comparing traditional and Bayesian analyses of selection experiments in animal breeding. Journal of Agricultural Biological and Environmental Statistics, v.5, p.240-256, 2000. 